\title{
Marine Protected Areas, Multiple-Agency Management, and Monumental Surprise in the Northwestern Hawaiian Islands
}

\author{
John N. Kittinger, ${ }^{1}$ Anne Dowling, ${ }^{2}$ Andrew R. Purves, ${ }^{2}$ Nicole A. Milne, ${ }^{1}$ and Per Olsson ${ }^{3}$ \\ ${ }^{1}$ Department of Geography, University of Hawai i $i$ at Mānoa, 445 Saunders Hall, 2424 Maile Way, Honolulu, HI 96822, USA \\ ${ }^{2}$ The Marine Biology Program, College of Natural Sciences, University of Hawai'i at Mānoa, 2450 Campus Road, Dean Hall, \\ Honolulu, HI 96822, USA \\ ${ }^{3}$ Stockholm Resilience Centre, Stockholm University, 10691 Stockholm, Sweden \\ Correspondence should be addressed to John N. Kittinger, jkittinger@gmail.com
}

Received 8 June 2010; Accepted 3 September 2010

Academic Editor: Robert J. Toonen

Copyright ( $) 2011$ John N. Kittinger et al. This is an open access article distributed under the Creative Commons Attribution License, which permits unrestricted use, distribution, and reproduction in any medium, provided the original work is properly cited.

Large, regional-scale marine protected areas (MPAs) and MPA networks face different challenges in governance systems than locally managed or community-based MPAs. An emerging theme in large-scale MPA management is the prevalence of governance structures that rely on institutional collaboration, presenting new challenges as agencies with differing mandates and cultures work together to implement ecosystem-based management. We analyzed qualitative interview data to investigate multi-level social interactions and institutional responses to the surprise establishment of the Papahānaumokuākea Marine National Monument (monument) in the northwestern Hawaiian Islands (NWHI). The governance arrangement for the monument represents a new model in US MPA management, requiring two federal agencies and the State of Hawai'i to collaboratively manage the NWHI. We elucidate the principal barriers to institutional cotrusteeship, characterize institutional transformations that have occurred among the partner agencies in the transition to collaborative management, and evaluate the governance arrangement for the monument as a model for MPAs. The lessons learned from the NWHI governance arrangement are critical as large-scale MPAs requiring multiple-agency management become a prevalent feature on the global seascape.

\section{Introduction}

Coral reef ecosystems comprise less than $0.1 \%$ of ocean space [1], but they are disproportionately important with regards to the critical role they play in tropical cultures worldwide [2]. In the Pacific, the history and cultural heritage of island societies are closely intertwined with coastal ecosystems [3], and coral reefs have long provided critical ecosystem goods, services, and sociocultural values that are the basis for Pacific Islanders' livelihoods, cultural practices, and traditional lifeways [4-6]. The social benefits that coral reefs provide are threatened, however, by a relatively small set of proximate, or direct, human activities that include overexploitation, landbased pollution, biological invasions, disease, and threats associated with climate change [7-9]. The principal response to reef ecosystem decline and degradation has been an increased focus on the implementation of marine protected areas (MPAs), which reserve ocean space for conservation.
MPAs serve primarily as a mechanism for ameliorating exploitation pressure, but often provide the institutional nexus by which other threats are addressed. MPAs exhibit a variety of forms but generally share a common goal to preserve resources and the ecosystems in which they are embedded.

Traditionally, the establishment of MPAs has focused on relatively small-scale reserves at the community level that focus on specific conservation targets (e.g., habitats or species). Attention has increasingly turned, however, to the establishment of large-scale MPAs and networks of marine reserves to achieve conservation goals at regional scales [10]. Conservation on regional scales allows for protection of larger proportions of marine habitat and different habitat types, spans the ranges utilized by errant marine megafauna, and preserves the dynamic biological processes required to maintain ecosystem integrity and resilience [11-13]. 
The establishment of MPAs has also become a primary focus as a means for implementing ecosystem-based management (EBM) in marine environments [14]. Marine EBM is defined as an integrated approach to the management of both social and ecological systems as opposed to traditionally fragmented sectoral approaches $[15,16]$. Though many frameworks for EBM have been advanced, the social dimensions of marine EBM have been identified as including governance arrangements, institutional dynamics, stakeholder engagement, and adaptive management [1720]. Comparatively less research has focused on these social dimensions versus the biological science of marine reserves, but it is a growing field that has been spurred on by an increased recognition of the importance of social science approaches in defining the pathways toward sustainable governance of linked social-ecological systems [21-27].

Large-scale MPAs face different challenges in governance and management than local and community-level MPAs, including multiple-agency management, overlapping statutory responsibilities and juridical zones, socioeconomic and political pressures, and a broader and more diverse constituency [28]. Compared with small-scale MPAs, however, relatively little literature has focused on the governance and management of large-scale MPAs, though some notable exceptions exist [28-32]. As marine EBM gains traction as the accepted approach in MPA management and planning $[14,18,30]$, natural resource management institutions are considering new means by which to integrate EBM. Management transitions to EBM approaches are complicated by differing statutory responsibilities, existing governance arrangements and institutional processes, all of which mediate the pathways that institutions utilize in environmental planning and management. Understanding the challenges that human institutions must meet to effectively navigate change is necessary if MPAs are to be social as well as biological successes $[21,30,33,34]$. This is particularly important considering the increased prevalence of multipleagency management structures associated with large-scale MPAs, where new challenges are presented as agencies with differing mandates and cultures work collaboratively to synthesize sectoral-based approaches into comprehensive EBM frameworks.

We investigated multilevel social interactions and institutional dynamics that characterized the management transition from the proposed national marine sanctuary to the surprise establishment of the Papahānaumokuākea Marine National Monument (monument) in the northwestern Hawaiian Islands. The objective of our research was to assess how the monument's multiple-agency governance structure and resultant management transition to institutional cotrusteeship have affected the institutional dynamics of natural resource agencies. We were also interested, in a more applied context, in identifying the major barriers to effective multiple-agency management, the solutions that have been employed to address these barriers, and more broadly, in assessing the governance arrangement for the monument as a model for MPAs. First, we provide a brief overview of the Northwestern Hawaiian Islands and the governance arrangement for the monument. Next, we briefly describe our interview-based research approach and methodology for analyzing qualitative data. Subsequently, we present the results of our research, summarized in a series of tables of coded interview responses and supported by summaries of direct quotations from respondents. We conclude with a discussion on the management transition to institutional co-trusteeship, the efficacy of the multi-agency governance structure as a model for marine conservation and offer policy prescriptions for improvement in multiple-agency management and planning for ecosystem conservation.

\section{Ecosystem Protections and Management in the Northwestern Hawaiian Islands}

The Northwestern Hawaiian Islands (NWHI) are a chain of islands, atolls, and shoals spanning approximately 2,000 kilometers to the northwest of the inhabited Main Hawaiian Islands (MHI), which together comprise the Hawaiian Archipelago in the central Pacific Ocean (Figure 1). Human habitation of the NWHI is restricted to a small population at Midway Atoll National Wildlife Refuge $(\sim 70)$ and Tern Island at French Frigate Shoals $(\sim 5)$; additionally, researchers, cultural experts, and other visitors inhabit various islands and atolls seasonally. Islands in the southeast portion of the chain were inhabited prior to European contact by Polynesian societies [35, 36], and Native Hawaiians recognize the islands as a sacred ancestral homeland from which life arises and to which spirits return after death [37].

Biologically, the various island, atoll, and coral reef habitats in the region support a rich array of species and populations, including a high proportion of coral reef species endemic to the Hawaiian Archipelago [39-41]. Coral reefs in the NWHI experienced impacts associated with exploitation and other human activities starting in the 19th century, but over the past $50+$ years reef ecosystems have been in a recovery mode [42]. With the exception of a few populations of vulnerable marine megafauna (e.g., the Hawaiian monk seal, Monachus schauinslandi) and some species that were commercially overexploited (e.g., lobsters, pearl oysters), intact populations now characterize the predator-dominated reefs in the NWHI [43].

Ecosystem protections predating the monument in the NWHI have a more than 100-year history and have been adequately summarized elsewhere [28, 44, 45]. The monument was established in 2006 by presidential proclamation under the American Antiquities Act of 1906 and includes the entire NWHI coral reef ecosystem [46, 47]. The proclamation created the largest protected area under US jurisdiction $\left(362,073 \mathrm{~km}^{2}\right)$, an area almost the size of the State of California (Figure 1). In 2010, the monument was inscribed as a UNESCO World Heritage Site for both natural and cultural value. Pursuant to the proclamation, full protections were to take effect in 2011 with the closure of the last remaining fishery (bottomfish fishery). In January 2010, however, the National Marine Fisheries Service signed an agreement with the remaining bottomfish fishers to surrender their federal fishing permits in exchange for compensation; as a result, all commercial fishing ended in January 2010. Extraction is now limited to subsistence take by visiting scientists, 


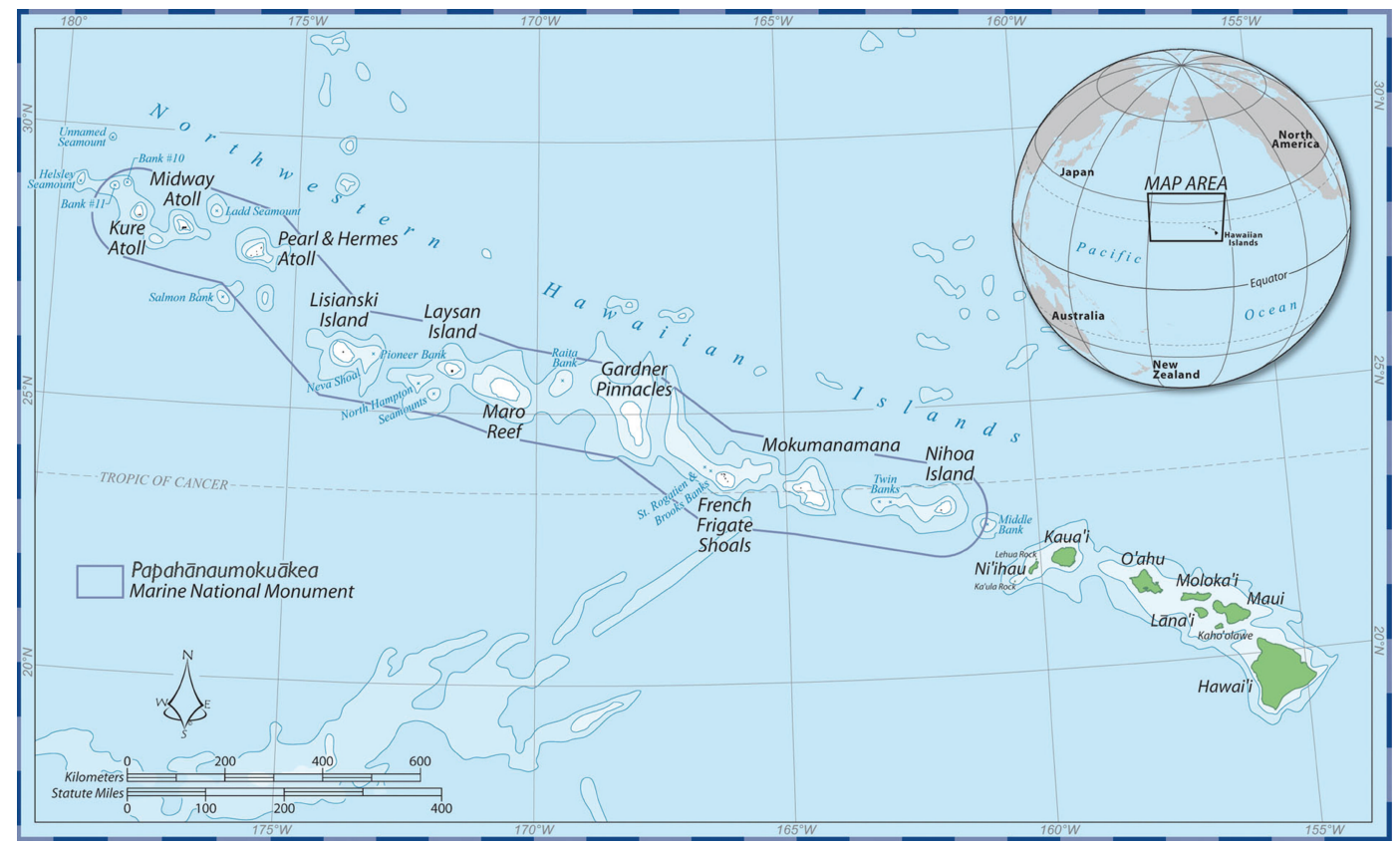

FIGURE 1: Map showing the Hawaiian Archipelago, comprised of the inhabited high islands of the main Hawaiian Islands and the uninhabited reefs, banks, and atolls of the Northwestern Hawaiian Islands. The boundary for the Papahānaumokuākea Marine National Monument is indicated in black. Map courtesy of the NOAA Papahānaumokuākea Marine National Monument Office.

residents of Midway Atoll and Native Hawaiian cultural practitioners, as well as minimal extraction for research purposes. Due to the limited number of permitted entries and negligible extraction for research, the monument is primarily considered a no-take reserve. Beyond exploitation impacts, NWHI coral reef ecosystems are threatened by human activities beyond the agencies' regulatory authority or the boundaries of the protected area. These threats include sea-level rise, biological invasions, marine debris, ocean acidification, coral bleaching, ship-based pollution, research impacts, contaminants associated with past occupations, and other threats $[48,49]$.

The proclamation establishing the monument was a major surprise to natural resource managers and stakeholders involved in the NWHI Coral Reef Ecosystem Reserve (a proto-sanctuary designation) [28], who had been engaged in a $5+$ year planning process for a national marine sanctuary designation $[28,50]$. The proclamation and associated regulations created a requirement for federal agencies to consult with each other in managing the NWHI. Following the proclamation, a memorandum of agreement (MOA) signed by the managing institutions established an institutional "co-trusteeship" of the protected area, requiring two federal agencies (the National Oceanic and Atmospheric Administration [NOAA] and the US Fish and Wildlife Service [USFWS]) and the State of Hawai' $i$ to manage the monument collaboratively as "co-trustees" (Figure 2). Though ostensibly the proclamation and MOA named three agencies as co-trustees, in actuality the co-trusteeship is comprised of seven different partner agencies that include different divisions of the primary co-trustee agencies as well as the Office of Hawaiian Affairs (Figure 2). Each of the co-trustee agencies has a long management history in the NWHI [45], and agencies have worked collaboratively in the past. But most of these collaborations were project specific, such as the multiple-agency approach to reducing marine debris [51] or interagency efforts on protected species management [52]. The establishment of the monument also further complicated the legal landscape of the area by preserving the existing management responsibilities and preexisting ecosystem protections established by federal and state agencies [28].

The institutional co-trusteeship represents a novel governance arrangement in US MPA management. Governance models for MPAs in the US have been traditionally based on an institutionally fragmented, hierarchical system, where a lead agency is the primary institution engaged in the formulation of policy and management actions with partner agencies. In creating a "co-trusteeship", the proclamation required state and federal co-trustee agencies to break new ground in institutional collaboration for co-management of the protected area [53] and ostensibly gave equal management authority to each of the co-trustee agencies. The establishment of the monument initiated a major management transition, where agencies and stakeholders were required to create new management structures and approaches to support the institutional co-trusteeship, including a Monument Management Board (MMB) that serves as the primary nexus for decision-making and policy formation among the seven partner agencies (Figure 2).

The first major co-trustee initiatives included the creation of a joint permitting process to review proposed activities in the monument, the development of a monument management plan, and the completion of an application 
(a) Senior Executive Board

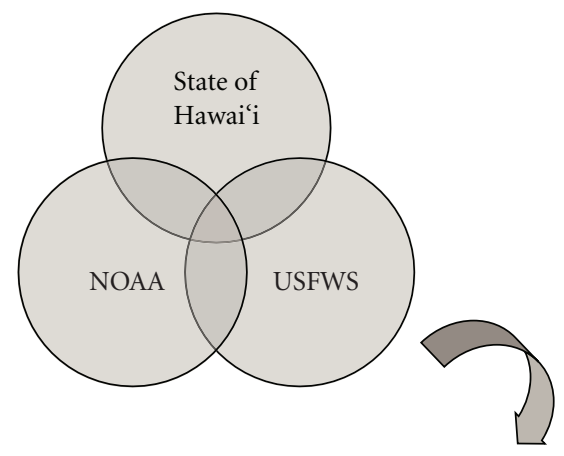

(b) Monument Management Board

\begin{tabular}{|c|c|c|c|c|c|c|}
\hline \multirow{2}{*}{\begin{tabular}{|c|} 
Office of \\
Hawaiian \\
Affairs
\end{tabular}} & \multicolumn{2}{|c|}{$\begin{array}{l}\text { State of } \\
\text { Hawai' } i\end{array}$} & \multicolumn{2}{|c|}{ NOAA } & \multicolumn{2}{|c|}{ USFWS } \\
\hline & $\begin{array}{c}\text { Div. of } \\
\text { Aquatic } \\
\text { Resources }\end{array}$ & \begin{tabular}{|c|} 
Div. of \\
Forestry \\
\& Wildlife
\end{tabular} & $\begin{array}{c}\text { ONMS } \\
\text { Monument } \\
\text { Office }\end{array}$ & $\begin{array}{l}\text { NMFS } \\
\text { Pacific } \\
\text { Region }\end{array}$ & $\left(\begin{array}{c}\text { Ecological } \\
\text { Services }\end{array}\right)$ & $\begin{array}{c}\text { NWRS } \\
\text { Monument } \\
\text { Office }\end{array}$ \\
\hline
\end{tabular}

FIGURE 2: Polycentric governance arrangement for partner agencies that manage the Papahānaumokuākea Marine National Monument. Operational decisions are made at the level of the Monument Management Board (b), which is overseen by a higher-level Senior Executive Board (a) comprised of senior managers from each of the three co-trustee agencies. The Monument Management Board is comprised of members from seven different resource management agencies. Abbreviations are as follows: NOAA: National Oceanic and Atmospheric Administration; USFWS: US Fish and Wildlife Service; ONMS: Office of National Marine Sanctuaries; NMFS: National Marine Fisheries Service; Div.: Division; NWRS = National Wildlife Refuge System (administers the Hawaiian and Pacific Islands NWR Complex, which includes Papahānaumokuākea Marine National Monument).

nominating the area for inscription as a UNESCO world heritage site. Each of these co-trustee initiatives required the agencies to break new ground in formulating policy and decision-making processes, and the monument management plan was particularly illustrative of the challenges that the co-trustee agencies were required to confront. The objective of the monument management plan is to coordinate a comprehensive management regime for cooperative stewardship of the monument. This required both cooperative co-trustee management of areas with joint or adjacent jurisdiction as well as specific agency responsibilities required by institutional policy or statutory mandates. To accomplish this, the monument management plan contains 22 action plans with specific strategies and activities to address six priority management needs.

\section{Methods}

We conducted in-depth, structured interviews with 23 natural resource managers from March-May 2009. Each interview was conducted in person and lasted 1-1.5 hours. Interviewees consisted of field staff, mid-level managers, lead representatives for agencies or subagencies (e.g., superintendents), and regional-level principals (Tables 1 and 2). Interviewees were from agencies on the Monument Management Board, related working groups, and institutional partnerships involved in management, planning, and research in the NWHI (Figure 2). Interviews followed accepted social science research methods and techniques $[54,55]$, and the confidentiality of participants' responses was protected. Our interview instrument consisted of a series of questions targeting specific aspects of the multi-agency management structure for the monument; these topical categories included (1) interagency processes and institutional co-trusteeship, (2) barriers and solutions to multiple agency management, (3) learning processes, (4) path dependencies, and (5) power dynamics.

Interviews were analyzed using a grounded theory approach [56, 57], which relies on an inductive analysis process that allows the researcher to develop theory on the research topics addressed while simultaneously grounding the results in empirical observations or data [58$60]$. Interviews were audio recorded and professionally transcribed and, together with notes taken during the interviews, responses were coded into conceptual categories. A comparative analysis was performed between the conceptual categories for each series of questions and the descriptive respondent data (i.e., agency affiliation, hierarchical position, and management tenure) to identify potential relationships between respondents' position and experience within their agencies and their perceptions of multiple-agency management. In addition to interviews, we conducted a comprehensive review and synthesis of secondary sources, including published reports, government publications, and policy documents. 
TABle 1: Summary of interviews by agency division for 23 natural resource managers involved in the management and planning of the Papahānaumokuākea Marine National Monument. Abbreviations are as follows: NOAA: National Oceanic and Atmospheric Administration; USFWS: U.S. Fish and Wildlife Service; NOS: National Ocean Service; NMFS: National Marine Fisheries Service; WPRFMC: Western Pacific Regional Fishery Management Council; Div.: Division.

\begin{tabular}{|c|c|c|}
\hline Institutional Co-Trustee & Agency Division & Interviews \\
\hline \multirow{2}{*}{ State of Hawai'i } & Div. of Aquatic Resources & 4 \\
\hline & Div. of Forest \& Wildlife & 1 \\
\hline \multirow{3}{*}{ NOAA } & NOS Monument & 6 \\
\hline & NMFS Pacific Region & 4 \\
\hline & WPRFMC & 1 \\
\hline \multirow{4}{*}{ USFWS } & Pacific Island Refuges & 4 \\
\hline & Ecological Services & 2 \\
\hline & & 1 \\
\hline & & 23 \\
\hline
\end{tabular}

TABle 2: Summary of interviews by hierarchical position rank for 23 natural resource managers involved in the management and planning of the Papahānaumokuākea Marine National Monument. The average tenure (years involved in management and planning in the NWHI) of interviewees was 6.98 years (median $=5$ years).

\begin{tabular}{lc}
\hline Hierarchal level & Interviews \\
\hline Regional or higher & 2 \\
Lead agency representative* & 6 \\
Manager & 10 \\
Staff \& field & 5 \\
\hline Total: & 23 \\
\hline
\end{tabular}

* Representative that acts as a lead for their agency or subagency in the MMB forum (e.g., superintendent).

\section{Results}

Interviews were conducted with managers representing all of the agencies involved in the planning and management of the monument and with individuals representing different hierarchies of decision-making authority (Tables 1 and 2). Interviews postdated the monument designation by $\sim 2.5$ years and generally focused on the period immediately prior to and after monument designation; occasionally respondents discussed longer histories of management and agency involvement in the NWHI for context. Generally, the number of interviews per agency and position hierarchy reflected the institutional capacity (number of dedicated managers) in each agency and at each decision-making level (Tables 1 and 2). Interviewees averaged 6.98 years of experience in managing or studying ecosystems in the NWHI (median $=5$ years), with a range from $<1$ to 30 years of experience among interviewees. Generally, coded responses were not associated with agency affiliation, tenure, or hierarchical position. As such, responses were grouped and major trends in responses and conceptual themes are presented below with respect to the primary topics addressed in interviews, including interagency processes, barriers to multiple-agency management, institutional learning, power dynamics and solutions.
4.1. Interagency Processes and Institutional Co-Trusteeship. Respondents provided information on inter-agency processes and relationships between partner agencies through a series of survey questions focused on agency relationships, management roles, dynamics of the Monument Management Board (MMB) (Figure 2), and perceptions of successes and failures of multiple-agency initiatives (Table 3). The principal challenge to the relationship between co-trustee agencies, as identified by $65 \%$ of respondents, was in the delineation of roles and responsibilities of each agency (Box $1(a)-(c))$. The second and third most commonly identified challenges were the differences between agencies' cultures, personalities, and visions (Box 1(d)) and disagreements about jurisdiction.

When asked about their perceived role in the management of the monument, unsurprisingly the majority of interviewees stated that their role was to fulfill their own agency's objectives; however, interviewees also recognized their role in collaborating with other agencies (Table 3 ). Respondents also mentioned that the designation increased their jurisdiction, provided their agency with a clearer role in resource management within the monument, and expressed their desire to "do what's best for the monument" and "conserve resources for future generations."

The maturation or evolution of the monument designation process was a recurring theme throughout the interviews, with many of the respondents recognizing the infancy of both the MMB and the planning process in general. When asked to comment on the dynamics of the MMB, respondents felt that the Board lacked sufficient leadership and was further hindered by differences in agency's cultures, personalities, and interpersonal relationships (Box 2(a)(d)). Comments on leadership and the MMB were primarily focused on turmoil that occurred prior to the formalization of decision-making processes for the MMB and related working groups.

There was considerable agreement among respondents as to the successes and failures of the monument designation process. A total of $57 \%$ and $35 \%$ of respondents respectively identified the completion of the monument management plan and the UNESCO World Heritage application as successful outcomes of the process, with $17 \%$ noting improved 
(a) "If you were to put it on a scale of 1 to 10, I'd still put (the) relationship...somewhere in the middle: 5, 6?... I can tell you, some of that comes from... unequal starting points, both organizationally and statutorily.... With the overall... theme that we (want to) be coequal. Yet, there's truth in the fact that we're not."

(b) "As soon as we became a monument, people started drawing lines in the sand. ... It was really interesting. ..because our cultures are so different, across NOAA (National Oceanic and Atmospheric Administration) and (the U.S.) Fish and Wildlife Services in particular, that it began a whole new way of engaging and trying to speak... trying to communicate with different languages."

(c) "When the monument was first designated, people made a concerted effort to really foster a team environment and I would say that since then it (has) disintegrated, and we've gone back to each entity being very territorial."

(d) "I think that there is kind of the day-to-day staff operation relationship, and then there's the kind of upper level superintendent type relationship, and I think those are very different. I think that the superintendent type relationship is strained, and then at the staff level, I think my impression is its pretty good."

Box 1: Co-trustee relations.

TABLE 3: Inter-agency processes: interviewee responses by conceptual category (a)-(d). Numbers in parentheses indicate number of responses from a total pool of 23 respondents.

(A) Co-trustees relationships and monument designation

Negative perceptions

(1) Challenge delineating roles and responsibilities (i.e., mandates, statutes, and jurisdiction) (15)

(2) Different agency cultures (i.e., personalities, perceptions, visions) (4)

(3) U.S. Fish and Wildlife Service jurisdiction challenged (3)

Positive perceptions

(4) Continued collaboration between agencies (3)

(B) Respondents' perception of agency role in the management of the monument

(1) Fulfill our agency's objectives (12)

(2) Collaborate with partners (4)

(3) Clearer roles and delineated responsibilities/ Expanded jurisdictions/resource caretaker (2/2/2)

(C) Dynamics of the Monument Management Board

Negative perceptions

(1) Agency cultures, personalities, and interpersonal relationships/Lack of leadership (8/8)

(2) Unclear roles and responsibilities (6)

Positive perceptions

(3) Management Board is maturing (4)

(D) Inter-agency initiatives: Success stories and failures

Successes

(1) Management plan completed (13)

(2) World Heritage application completed (8)

(3) Joint permitting process/interpersonal relationship improved (4/4)

Failures

(4) Interpersonal relations and unprofessional behavior (6)

(5) Joint permitting process (4)

interpersonal relationships. Fewer numbers of respondents identified failures in the process; however, those of concern were strained interpersonal relations and displays of unprofessional behavior (Table 3 ). The joint permitting process, which enabled multiple-agency review of proposed activities, was viewed as a success by $17 \%$ of respondents, while an equal number of respondents stated that the permitting process still required considerable work and was a "messy" process.

4.2. Barriers to Multiple-Agency Management. A total of $83 \%$ of respondents identified institutional cultures and management styles as the primary barrier to successful multiple-agency management (Table 4). Interviewees perceived a lack of understanding and acknowledgement of different approaches to management, differences in terrestrial versus marine management styles, institutional rigidity, and different ways of communication among agencies (Box 3(a)-(g)). The second and third most commonly cited barriers were interpersonal relations (61\%) (i.e., lack of trust, unprofessional behavior), and jurisdictional issues and legal authority (43\%) (i.e., authoritative rigidity, interpretation of mandates, and unfamiliarity with regulations) (Box 3(f)(k)).

When asked about persistent disagreements or sources of conflict affecting the process, respondents focused on many of the same concerns that surfaced in the previous question, namely legal and jurisdictional issues (57\%) and interpersonal relations (26\%); however, they also mentioned disagreements and disparities in funding and resources between agencies (26\%). Though we didn not specifically target data on conflict intensity, examples provided by respondents indicated that conflicts exhibited a range of intensities, from inefficient transactions between partners to seriously disruptive interpersonal conflicts that resulted in breakdowns in partner agency relationships. When pressed further about persistent conflicts, respondents commonly commented on strained interpersonal relations and disruptive behavior (Box 3(g) and (h)) and cited the impact that managers' personalities, leadership and management style can have on interagency collaborations and perceptions of success or failure. Other responses on sources of conflict are related to funding disparities, which mediated the inability 
(a) "We entered this process not knowing each other's agencies all that well.... And we rapidly learned that our agencies, even though we operate under some of (the) same laws and regulations that the other (agencies do), we interpret them very differently. So that set up some additional controversy to begin with, I think exacerbated by differences in personalities.... It's very difficult to sit through a meeting and be yelled and screamed at, to be very honest. And it has happened many, many, many times."

(b) "There have been really good times when people really rolled up their sleeves and really worked...towards a common goal, and there have been times when I've had some of my coworkers. . .qualify some of the later meetings. . .as abusive and. . . a hostile work environment."

(c) "Maybe it's a lot to ask of. ..that young (of) an organization...but it needed more leadership at all agency levels, between all the agencies involved.... And if we all take a look at the place and are guided by that, we can find ways within our agencies to. . .support what's going on here and to make the best decisions. And instead, it just seems a lot of times to kind of get mired in the more stereotypical government approach of being governed by the regulations as opposed to, you know, what you want to see in that area."

(d) "We had to figure it out from the moment at which the proclamation went into effect with no guidance, and we had to start managing this place as well as write a management plan, develop a world heritage document...we had (to) invent the wheel as we are going along."

Box 2: Dynamics of the monument management board.

TABLE 4: Barriers to multiple-agency management: interviewee responses by conceptual category (e)-(h). Numbers in parentheses indicate number of responses from a total pool of 23 respondents.

(E) Primary barriers to the multiple-agency management of the monument

(1) Institutional culture and management styles (19)

(2) Interpersonal relations (14)

(3) Jurisdictional issues and legal authority (10)

(F) Inter-agency conflicts

(1) Legal and jurisdictional issues (13)

(2) Funding and resources/interpersonal relationships (6/6)

(G) Primary source or root cause of conflict

(1) Jurisdictional issues and legal mandates (12)

(2) Different agency cultures and approaches (11)

(3) Interpersonal relationships (9)

(4) Monument process and design (8)

(H) Institutional cultures and interagency relationships

(1) Approach to management (6)

(2) Disparities in funding and resources/Jurisdictional issues and mandates $(2 / 2)$

to fund adequate staff and to source transportation to access the NWHI.

Interviewers asked respondents to comment on their perceptions of the root causes of persistent conflicts, and again interviewees focused on jurisdictional issues and legal mandates, specifically misunderstandings derived from the lack of clear mandates (52\%), differences in agency approaches (48\%), and interpersonal relationships (39\%) (Box 4(a)-(f)). A total of six respondents felt that management approaches were most directly impacted by differences in agency culture. Respondents cited specific differences between agency approaches, which included references to perceived and actual differences in the types of management activities, statutory requirements, and institutional cultures.
TABLE 5: Institutional learning: interviewee responses by conceptual category (i)-(k). Numbers in parentheses indicate number of responses from a total pool of 23 respondents.

(I) Mechanisms for interagency learning

(1) Interagency meetings (9)

(2) Collaboration (8)

(3) Evolution of process/communication (7/7)

(J) Evidence of learning outcomes

(1) Increased collaboration on documents and processes (11)

(2) Institutional maturation and processes/working relationships improved (7/7)

(3) Sensitivity and problem avoidance (6)

(K) Shifts in approach due to institutional learning

(1) Sensitivity and problem anticipation/evolution and maturation of the process (9/9)

(2) Collaboration and cooperation on management (8)

4.3. Institutional Learning. Interviewees were asked to indicate whether the monument designation process has resulted in co-trustee agencies learning about their partner agencies, to describe how learning was enabled, and provide examples of learning outcomes. Respondents cite four common processes or mechanisms where learning has occurred: interagency meetings $(39 \%)$, collaborative initiatives (including workshops, retreats, and informal gatherings) (34\%), evolution of the management process (30\%), and communication (30\%) (Table 5). Respondents viewed interagency meetings as opportunities to engage with the larger group, to plan together, and to learn about other agencies and their processes. Five respondents noted that the presence of deadlines served to increase collaboration between agencies, and seven interviewees cited improvements in both formal and informal communication throughout the monument management planning process. The replies of seven respondents spoke to the maturation of the process; specifically how 
(a) “... the lack of understanding and acknowledgement of other agency's mandates and other agency's processes.”

(b) "I think that [the] primary barrier is that approaches on land are very different than approaches in the water and that people who have land holdings really look at the boundaries and the fences and say, "this is ours" and have a much more...rigid approach and are less willing to let go of how things have been done previously under that kind of jurisdiction than what happens in the ocean...”

(c) “... when people get wrapped up in their agency versus the place and look for reasons that their regulations or policies can restrict their abilities to work versus looking at the ways to creatively find ways to actually work together to do it. It's very very frustrating."

(d) "These....natural resources are also cultural resources from a Hawaiian epistemology and cosmological point of view. Our history, our eldest ancestor out of darkness is the coral polyp. When you manage from that, and you manage with the 7 generational view, it's very different to somebody managing with a 15-year management plan mind, even a single generation mindset, a budgetary 3 -year cycle or "how long am I gonna be stationed here' view."

(e) "I guess, and this sounds weird, but I'd have to say traditional thinking. You know, there's ways that agencies think. They develop a group think, and I've alluded to the fact that unless people are willing to kind of ease up, break out of the old mold and be a bit flexible, this thing can all come off the rails in a hurry."

(f) "The other is simply personalities. I mean to make this work, it's tremendously dependent on a set of personalities that can interact well together and trust each other. And we have had personality conflicts."

(g) “...the individual personalities have played the largest role in the limited success and bigger failures of this whole process."

(h) "They have very strong personalities and I think that that has actually been part of the issue of breakdowns and communication. I think they are all very good at fighting for their piece but have missed the picture that they should be fighting for the monument as a whole and not for their piece of the monument, and I think that has been a real breakdown.”

(i) “I don't think there should be any barriers between interagency management. ... people should be able to jointly manage these areas because the resources don't have lines down them and you know, it's pretty seamless when you're out there. So, I just think whatever way your agency does stuff, whatever history you have, whatever beliefs you have, you've got a-you have an obligation as a resource manager to sit down at the table with everybody else and just jointly manage it.... I don't understand why there were the problems.... The MMB heads are all high-level, highly skilled, highly trained people. They should be able to sit down at a table and figure it out."

(j) "I think one is just a lack of clarity from the get-go of the jurisdictions... of the different agencies involved in this. (The boundaries were) unclear... as to who exactly was responsible for what."

(k) “...that law says that all national wildlife refuges are closed to all users until specifically opened to a use. That's different in Alaska because they have a different law, but for your purposes here in Hawaii, all those refugees were closed until opened, and we never opened the Hawaiian Islands National Wildlife Refuge or the Midway Atoll National Wildlife Refuge to commercial fishing."

Box 3: Barriers to multiple-agency management.

(a) "There are still some core legal issues that we're starting to work through that are causing points of conflict between you know, between NOAA (National Oceanic and Atmospheric Administration) and (the U.S.) Fish and Wildlife Service. Its wilderness and what wilderness means. It definitely means something to them and doesn't mean anything to us."

(b) "We would have less conflict if we could clearly articulate what our statutory authorities are."

(c) "(A) lot of it had to do, I think, with the pressure of getting the management plan. We had pressure to get our jobs done, pressure to get the management plan done before the end of the year. We were under a [deadline]...in a forced time frame when there is so much confusion... emotions were high, stress level was high.... You know what, just get the management plan done. We focused on that, got the thing out."

(d) "One is the interpersonal relationships or the personality conflicts at the ground level... I would say the interpersonal relationships were the number one."

(e) "I think, we all are competing for limited resources."

(f) "I still think it's the corporate difference, the corporate culture difference and jurisdiction...that everything stems from those." 
as time progressed agencies recognized the importance of flexibility and realized the need for institutional change.

Interviewee responses provided evidence of learning, including (1) the collaboration of agencies on formal documents, including the monument management plan and the UNESCO World Heritage application, (2) improvements in working relationships and institutional processes, and (3) an increased attention to problem avoidance, coupled with an improved understanding and sensitivity to partner agencies' positions and objectives. Respondents indicated that evidence for learning was manifested as shifts in management approaches, decision-making processes, and problem solving techniques. Respondents cited a greater sensitivity to agency cultures and problem anticipation, noting that as time progressed issues were addressed up front, agency responses could be anticipated, and there was a heightened awareness to rules and protocols. Responses indicated that through collaboration, agencies gave greater consideration to each other's ideas and approaches, and some recognized the need to formalize the organizational structure of the monument to advance the process and clarify rules and responsibilities.

4.4. Inter-Agency Power Dynamics. Though the proclamation created a co-trusteeship that ostensibly provides each partner agency with equal authority, respondents indicated that power dynamics were unequal between the various agencies responsible for resource management within the NWHI. Respondents cited four instances in which disparities in funds and resources among partner agencies affected the management process, including (1) uneven distribution of power $(39 \%)$, (2) the precedence ascribed to agency priorities and participation (17\%), (3) access to transportation and logistical support (13\%), and (4) impacts on working relationships (9\%). Respondents perceived an uneven distribution of power and resources across the agencies, remarking that, while some agencies hold monetary power, others retain power in their jurisdiction over land and water resources. For example, the perception noted by several respondents is that NOAA holds increased power over USFWS and the State of Hawai' $i$ in terms of funds, facilities, and staffing; however, the State and USFWS have a history in the NWHI and a jurisdictional presence that affords them a unique level of power and participation in management and planning processes (Box 5(a)-(e)). Respondents perceived discrepancies in funding as affecting the working relationships relationships between resource managers, as well as an agency's ability to participate in research and management projects, and to secure adequate transportation and access to the NWHI. Actualized power was reflected primarily in the extent to which a given agency had resources and how these resources were distributed among partner agencies (e.g., funds for specific initiatives, transportation to the NWHI). Additionally, actualized power was manifested in control over physical access points in the NWHI (e.g., Midway Atoll National Wildlife Refuge) and through legal mandates dictating specific processes (e.g., permitting or planning requirements) that affected the activities of partner agencies.
TABLE 6: Solutions for multiple-agency management: interviewee responses by conceptual category $(\mathrm{L}-\mathrm{N})$. Numbers in parentheses indicate number of responses from a total pool of 23 respondents.

(L) Effective strategies for integrating efforts in multiple-agency management

(1) Adopting formal processes and structures (14)

(2) Collaborative interagency initiatives (10)

(3) Common purpose/Involvement of higher-level management in decision making/Increased familiarity and education about other agencies (4/4/4)

(M) Mechanisms that trigger the development of new strategies and structures

(1) Conflict and disagreement/Recognition of problems and needs (7/7)

(2) Requirement, deadline, or mandate (4)

(3) Involvement of higher-level management (3)

(N) Mechanisms that diffuse new ideas and innovations through interagency organizations and relationships

(1) Formal processes (11)

(2) Informal processes (6)

4.5. Solutions for Multiple-Agency Management. Respondents identified several strategies that have been effective in facilitating multiple-agency management, including adopting formal processes and structures (61\%) and interagency collaborative initiatives (43\%) (Table 6). Additionally, a total of $17 \%$ of respondents recognized the involvement of higher-level management, the identification of a common purpose during planning processes and interagency interactions, and an increased familiarity and understanding of other agencies as effective techniques in the designation process.

The development of new strategies and structures was driven primarily by the recognition of a problem or need, as well as the presence of conflict or disagreement, and secondarily driven by the requirement of a deadline or mandate, or through the involvement of higher-level management. Respondents cite the diffusion of new ideas and innovations primarily by formal processes (i.e., working groups, $\mathrm{MMB}$ meetings) but also through informal mechanisms of communication, such as social gatherings, and through relationships between managers at partner agencies.

Throughout the survey respondents provided several suggestions for ways to improve multiple-agency management. When asked to describe broader solutions to comanagement, respondents cited the importance of increased collaboration and agency flexibility (30\%), the need for greater leadership (13\%), and the need to equalize funding and resources across agencies (9\%). Additional suggestions that surfaced throughout the survey include the need to clearly define agency roles and responsibilities, increased understanding of legislative mandates, the prioritization of resource allocation, the establishment of a single management body, improvement in interpersonal relationships among agency members, and an effective and streamlined public engagement procedure. 
(a) "NOAA [National Oceanic and Atmospheric Administration] has tons of money, USFW (U.S. Fish \& Wildlife Service) has less, and the State (of Hawai i i) has very little, so naturally this effects who can do what and who put more resources into the NWHI management."

(b) "Suddenly... sanctuaries get seven million dollars. . .so they're in charge of you know, they have most of the money to implement things. But ironically, you know, once it did not become a sanctuary and it became a monument, the sanctuary program probably had the least amount of legal jurisdiction in comparison to say, (NOAA) Fisheries or (the U.S.) Fish and Wildlife Service. And so it created an awkward power dynamic, where you know, the person in control of most of the money wasn't the one who necessarily had a lot of the other authorities."

(c) "I think the issues of equality or the problems, they're not equal in my opinion. Fish and Wildlife Service is...not the land owner but they have the land which is power. NOAA is water and has lots of money and resources. That's power. The state of Hawai' $i$, I think $90 \%$ of all the activities that occur in the monument are actually in state waters so maybe you could call that power, but they don't have any staff. They have very little staff, and they have little to no resources especially given the past, you know, year."

(d) "The power I think that the state has is the community... is the voice of the community much more so than the other agencies, and likewise OHA (Office of Hawaiian Affairs), and so everybody has shared power at different levels. NOAA's power does not just come from the money either. They're very visible and effective."

(e) "When you have money for staff and resources and projects and boats and access, you're gonna have inequitable power."

Box 5: Power dynamics.

\section{Discussion}

The surprise designation of the NWHI as a marine national monument created a major change in the governance arrangement that initiated a management transition among partner agencies from a hierarchical and sectoral model to a polycentric governance system and institutional cotrusteeship. Polycentric institutions have been characterized as nested, quasiautonomous decision-making units that operate at multiple scales and nurture diversity for dynamic responses in the face of change and uncertainty [61]. It has been posited that complex, multilevel governance systems exhibit a diversity of responses and capabilities that contrast. with traditional centralized governance units and thus may possess an element of adaptability that may convey resilience to disturbances or crises (human and natural) [61-63].

In the NWHI, polycentric governance systems were first established through the creation of novel, multi-agency management structures and an agreement among agencies to work toward consensus in decision-making processes [53]. The Monument Management Board (MMB) served as the primary nexus for multiple-agency decision-making and was overseen by a higher-level Senior Executive Board, which was occasionally activated in the case of disagreements at the MMB level (Figure 2). Below the level of the MMB, working groups were formed to address specific management needs and networks of individuals at different agencies with related work descriptions worked collaboratively to facilitate collaborative management (e.g., agency permit coordinators). These polycentric, multi-agency management structures were formulated based on the need to move from a hierarchical, fragmented decision-making process towards more integrated processes, and the establishment of these governance structures required the agencies to break new ground in rule formulation, operating procedures, and protocols for decision-making.
We argue that the monument designation has resulted in some institutional transformations among partner agencies, but not all of these transformations have been adaptive. Transformability has been defined as the capacity to cross thresholds or transcend rigid pathways to provide an opportunity to develop along new trajectories [64]. By adaptive we mean changes in institutions that convey the capacity to adjust responses dynamically to changing external drivers and internal processes (Table 7). Adaptive responses convey advantages in allowing institutions to develop along new trajectories or pathways, whereas transformations are described more simply as abandoning more rigid, pathdependent approaches in favor of increased institutional flexibility. Adaptive responses by partner agencies seem to be limited to few collaborative initiatives and interagency processes, where institutional learning, accrued experience in the co-trusteeship arrangement, and new knowledge have resulted in the adjustment of agency approaches and decision-making systems as a response to both external drivers and internal dynamics. Adaptive responses include specific initiatives such as the joint permitting program, the multi-agency environmental impact review process, and the formalization of protocols governing the MMB, all of which required agencies to break new ground in rule formulation and adopt new decision-making pathways. Institutional learning processes, which we discuss below, appear to have provided the impetus for these adaptive responses. In contrast, institutional transformations have resulted in shifts in institutions toward more flexible approaches and sensitivity to partner agencies and appear to have occurred throughout the transition to co-trusteeship for the NWHI. Institutional transformations were most commonly manifested in institutions' shifts in their approach to partner agencies, including increased sensitivity and awareness of partner agencies' mandates, mission, and organizational cultures. 
TABLE 7: Concepts and definitions in ecosystem-based management and institutional resilience.

\begin{tabular}{ll}
\hline \multicolumn{1}{c}{ Concept } & Definitions and key criteria \\
\hline Adaptive management & $\begin{array}{l}\text { Managing institutions purposefully formulate policy as an uncontrolled, nonreplicated experiment, } \\
\text { monitor the results of the strategy, and iteratively revise their approach in order to adapt to changing } \\
\text { social and ecological conditions. } \\
\text { Key criteria: multiple steps in a prescribed cycle of actions; monitoring results used in evaluation of } \\
\text { policy or management actions; purposeful implementation }\end{array}$ \\
\hline & The abandonment of more rigid, path-dependent approaches in favor increased institutional \\
flexibility as a purposeful response or as the result of internal dynamics or external drivers; \\
transformations can result in the capacity of institutions to cross thresholds or transcend rigid \\
pathways to provide an opportunity to develop along new trajectories. \\
Key criteria: markers of increased institutional flexibility; Abandonment of previous protocols or \\
procedures in favor of new methods or approaches
\end{tabular}

Institutional maturity and accrued experience in the co-trusteeship also appears to be a major determinant in whether responses result in transformations and whether these transformations are adaptive. Our analysis primarily focused on a retrospective view of the periods immediately prior to and after monument designation and thus can be considered a snapshot of an ongoing and dynamic process. The maturation of the co-trusteeship was reflected in the adoption of formal rules and protocols for decision-making processes by partner agencies, and transformations in individual agencies (e.g., shifts in approach toward partners, increased communication and sensitivity toward partners) also appear to evidence an evolving maturation process internal to individual agencies.

Below, our analysis focuses more fully on three specific topical areas germane to the monument designation and management transition. These include our assessment of the barriers to effective institutional co-trusteeship and the solutions employed to surmount these barriers. Next we discuss the role of institutional learning in institutional transformations and conclude with an assessment of the monument as a model for US MPAs.

5.1. Barriers and Solutions to Effective Institutional CoTrusteeship. Our analysis reveals that the relationships between co-trustee agencies were complicated at the outset by several barriers that presented challenges to the partner agencies. Barriers to effective institutional co-trusteeship have been both formal and informal and were first confronted by managers in the partner agencies during the planning process for the monument, where multiple institutions and stakeholders worked to establish a common vision and goals and collaborate on strategies and interagency initiatives (e.g., the monument management plan).
Formal barriers include differing statutory responsibilities, jurisdictions, and legal regulatory challenges associated with integrating management legislative mandates (legal regimes) and decision-making hierarchies employed by the different managing agencies. Informal barriers, in contrast, include differences in agency formulation and implementation of policy, operations, interpretations of responsibilities, management activities, and permitting requirements (regulatory approach), and differences in agency philosophy, core ethics, institutional culture, and guiding principles (management paradigms).

Partner agencies were primarily able to confront and successfully resolve formal barriers that created contention for issues such as the creation of a joint permitting process, a multi-agency monument management plan, and other initiatives. Respondents viewed the completion of these multi-agency initiatives as evidence of successful collaboration among partner agencies (Table 3 ), despite citing persistent jurisdictional issues and differing legal mandates as a root cause for conflict (Table 4). These results suggest that interagency collaborations have largely been successful in resolving formal barriers. For example, significant resources were invested by legal teams from each of the partner agencies to agree on a joint permitting process, which resolved many of the outstanding issues among partner agencies on multi-agency review for proposed activities in the monument. This process required significant investment to satisfy the agencies myriad statutory responsibilities while creating a multi-agency review process for proposed activities in the monument. Attorneys from co-trustee agencies worked through jurisdictional and statutory requirements via interagency conference calls and meetings, and agencies worked toward an agreement on a common permit form and review procedure. Other, more informal mechanisms were 


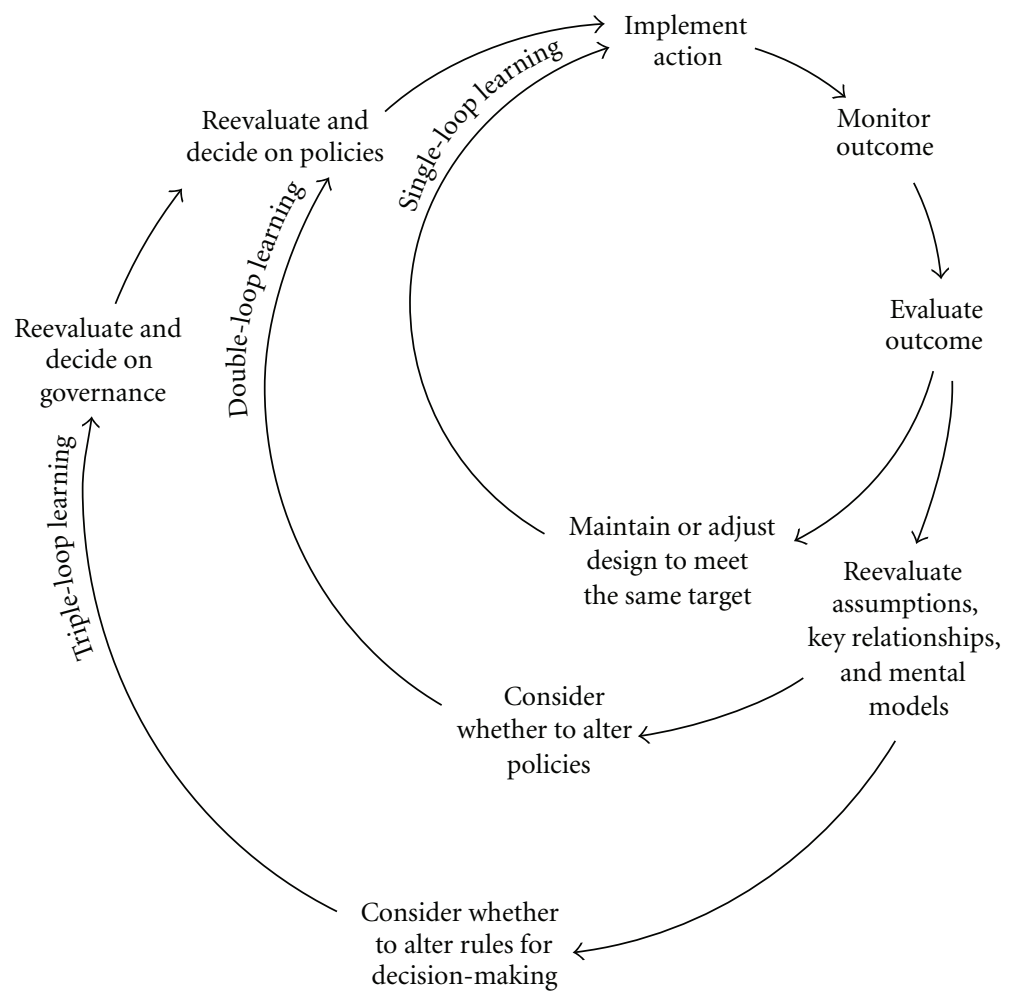

FIgURE 3: Different pathways and outcomes of institutional learning. Triple-loop learning involves the same re-evaluation of assumptions and models as double-loop learning but considers whether to alter rules for decision-making and fundamental changes in governance systems. Reprinted with permission from Folke et al. (2009:105) [38].

also employed by partner agencies to resolve or skirt formal barriers-for example, managers made a tacit agreement not to use the " $j$-word" (jurisdiction) in decision-making contexts.

Informal barriers have, however, proved to be more resistant to solutions. These barriers were identified by respondents as including differences in agency culture, interpersonal relationships, and approaches to management (Tables 3 and 4). Agency culture was defined variably by respondents as including the core ethic, management paradigms and approach by the differing co-trustee agencies, as well as the interpersonal relationships and "group think" that develop within institutions (Box 6). Respondents indicated that ideological clashes and interpersonal relationships originated in part due to differences in agency cultures and institutional rigidity, which occasionally caused breakdowns in interagency relationships. Differences in power among partner agencies, particularly in funding disparities also contributed (Boxes 3 and 4). Our results suggest that these informal barriers have been addressed primarily through learning processes and increased trust and social capital among agency managers, which over time caused agencies and managers to abandon more rigid approaches in favor of increased flexibility as they learned more about their partners.
5.2. The Role of Institutional Learning. Institutional learning has been defined as the "detection and correction of error [65]" through the "process of improving actions through better knowledge and understanding" [66]. Institutional learning provides an adaptive mechanism that informs how agencies respond to change, particularly in the face of crisis or surprise [38]. Adaptive institutional learning can take three forms, including (1) "single-loop" learning, in which institutions monitor and evaluate outcomes and maintain existing management approaches, (2) "double-loop" learning, where institutions re-evaluate their management actions or policies based on the recognition that change may be required, and (3) "triple-loop" learning, where institutions go beyond evaluating their approach and consider changes in existing rules for decision-making and governance models to meet management goals and objectives (Figure 3 ).

In this case study, institutional transformations appear to be the result of institutional learning processes. Adaptive responses were mediated by deeper learning processes, which in some cases caused institutions to alter their decisionmaking pathways and protocols and develop along new pathways in response to the co-trusteeship governance arrangement. Deeper learning processes include double and triple-loop learning, which can result in major changes in management approach and provide a mechanism by 
(1) "Agency culture to me means "what's your core ethic?" ”

(2) "By culture I mean. .. just the way agencies operate"

(3) "Culture differences (are) just in terms of how you approach issues"

(4) "A culture is nothing but a series of. ..relationships that manifest themselves. ..collectively, in a group of people....I think you really have to take the time to get to know people."

(5) "What I'm kind of alluding to when I say agency culture (are different interpretations of) definitions...uses of these terms"

(6) “...you know we have our own culture. We have our own way of doing things. We have our own way of thinking”

Box 6: Respondents' definition of agency culture.

which institutions remain flexible and resilient to changing ecological and social conditions [38, 67-69]. In contrast, transformations can be negated or stymied by institutional path dependencies, or "lock-ins," that institutions develop through time and which constrain future choice sets [70, 71].

For the NWHI, respondents indicated that several mechanisms enabled learning opportunities, including interagency meetings and processes, collaborative initiatives, and formal and informal communications (Table 5). Successful completion of interagency collaborative initiatives (e.g., the monument management plan; UNESCO World Heritage application) was commonly cited as tangible evidence of learning outcomes. Learning outcomes were also manifested as shifts in approaches to interagency collaborations and greater sensitivity and anticipation to partner agencies in the management process (Table 5). Double- and triple-loop learning processes appear to have initiated adaptive transformations in at least three collaborative initiatives, where partner agencies made significant shifts in decision-making processes and developed along new pathways as a result of learning. These initiatives include the decision-making process for the $\mathrm{MMB}$, which underwent formalization in protocols, meeting structure and leadership processes, and the multi-agency environmental impact review process. The joint permitting process for proposed activities in the NWHI was also significant in that it required agencies to formulate new decision-making patterns and processes. Respondents indicated that changes in these processes constituted major challenges to agencies, and changes as a result of these initiatives were beneficial to working relationships and other interagency collaborations (Table 5). These shifts in approach suggest that the institutional co-trusteeship has enabled transformative learning processes (double- or tripleloop learning), but evidence of persistent barriers also points to the interplay between learning processes that facilitate interaction and institutional path dependencies that give rise to conflict and tension.

Lock-ins or path dependencies seem to have structured early interactions among partner agencies in the planning process for the monument and were at least partly responsible for conflicts between partners. Path dependencies were reflected in respondents' descriptions of differences in the legal and statutory responsibilities underpinning their specific agency's role and objectives in the co-trusteeship as well as their approach to management and institutional culture. For example, partner agencies differed significantly in their approach to satisfying requirements of the National Environmental Policy Act, which requires US agencies to engage in an assessment of potential environmental impacts for management activities. Though each of the federal agencies and their divisions were beholden to the same statutory requirements, their approach to satisfying these requirements differed significantly and the process required major investment in collaborative meetings to agree on a common process and approach. As in the joint permitting process, agency attorneys and policy experts collaborated to resolve statutory responsibilities and agreed on a common process that fulfilled each of the co-trustees' requirements. Other path dependencies included differences among partner agencies in the definitions for core terms, differentiating between what constitutes "research" versus "management," and disparities in hierarchies of authority in collaborative decision-making processes. Generally, institutional learning processes served to mitigate conflict associated with path dependencies over time as institutions moved toward more flexible approaches, but experience with the co-trusteeship process and the natural maturation of agencies and the polycentric MMB forum also served to diminish conflict.

\subsection{The Institutional Co-Trusteeship Model: Lessons Learned} from the NWHI. Promoting interagency coordination in managing the marine environment has been identified as a major need by two high-level reports on US ocean policy $[72,73]$, but it is largely unknown whether institutional collaboration leads demonstrably to improved environmental outcomes [74]. Institutional collaboration provides advantages in reconciling sectoral approaches into cohesive EBM approaches, but barriers to effective co-trusteeship may also negate comprehensive management and planning and the establishment of sustainable, adaptive governance structures $[75,76]$.

Adaptive management, whereby managing institutions formulate policy as an uncontrolled, nonreplicated experiment, monitor the results of the strategy, and iteratively revise their approach in order to adapt to changing social and ecological conditions [68, 77-79] (Table 7), is posited as 
a major component of EBM [17, 20]. Dietz et al. characterize the adaptive process as akin to a coevolutionary arms race, where a set of rules created for a particular set of social and ecological conditions can erode in the face of dynamic and shifting social, economic, and technological developments [75]. Learning in the adaptive management cycle provides a process by which institutions can retain transformability and remain flexible in the face of change [67]. Double- and triple-loop learning, in particular, may convey adaptability to institutions by providing the impetus for agencies to reevaluate their approach, including rules, regulations, and governance approaches. Alternatively, institutional rigidity and path dependencies can negate adaptive responses and give rise to conflict, entropy, or institutional collapse, which in turn can negatively affect ecosystem integrity and resilience.

Can adaptive management, however, be accomplished through institutional co-trusteeship? The multi-agency governance structure for the NWHI has resulted in increased complexity in management and planning processes, with resultant declines in efficiency. For example, agencies have devoted significant resources to reconciling legal and regulatory regimes, management approaches, and differing goals and objectives. Institutional co-trusteeship has also generated conflicts associated with power dynamics and other disparities, which contributed to inequality in relationships among partner agencies (e.g., funding disparities; control of access). Despite these persistent issues, barriers to successful institutional co-trusteeship have been surmounted by a portfolio of successful approaches-or transition strategiesemployed by partner agencies. Formal barriers have been primarily resolved through interagency collaborations on specific rules or legal responsibilities, adopting formal processes and structures for decision-making, and informal agreements among managers to avoid issues of contention and work towards consensus. Informal barriers have been resolved by a number of mechanisms, including institutional learning and maturation in the co-trusteeship, which have strengthened partnerships through time and served to reduce conflict in partner agency interactions.

Our results suggest that adaptive management can be achieved through institutional co-trusteeship but that planning processes for similar multi-agency governance arrangements must seriously consider the formal and informal barriers that may exist between partner agencies prior to crafting governance arrangements. Ideally, formal barriers could be clearly identified via in-depth consultations with partner agencies beforehand (e.g., jurisdictional issues), and mechanisms could be explored to minimize potential sources of conflict or contention (e.g., funding disparities that may drive power dynamics). Interagency consultations on specific initiatives in the NWHI suggests that the existence of formal barriers and their associated path dependencies can often spur transformations in partner institutions toward more flexible approaches that minimize conflict associated with formal barriers. In some cases, deeper learning processes through close collaboration have resulted in adaptive responses from institutions (e.g., joint permitting, environmental impact assessment, MMB formalization).
Our results also suggest that multi-agency governance arrangements will be more adaptable if mechanisms are incorporated to allow for iterative evaluations of the efficacy of the governance arrangement, including the rules that structure working relationships and decision-making processes. Such mechanisms may be effective in maintaining flexibility in the relationships between partners and allow the institutions involved to iteratively recraft the way partners engage if current arrangements are not optimal.

Informal barriers, in contrast, have been more resistant to solutions but may be surmounted through processes that rarely receive much attention. These include (1) establishing common languages, goals, and objectives and a shared identity early in the process, (2) consciously enabling institutional learning processes that increase flexibility and sensitivity to partner agencies, (3) maturation of planning processes and establishment of formalized processes and frameworks for interagency collaboration, and (4) building social capital among managers that is developed through repetitive and reciprocal interactions that build trust. We suggest that identifying specific mechanisms by which these informal processes can be promoted (e.g., retreats, facilitated workshops) may be effective in surmounting informal barriers (e.g., agency cultures and path dependencies) and in fostering a high level of innovation in organizational cultures necessary to address cross-cutting and emerging issues in marine EBM.

Dramatic shifts in ecological or social conditions can give rise to periods of crisis or surprise during which institutions and the connections between them are most open to dramatic transformation [71, 80, 81]. The monument designation for the NWHI was itself a major surprise, and initiated institutional transformations as a novel governance system forced partner agencies to move towards polycentric management. It remains unclear, however, how these institutional transformations have translated into achieving ecological restoration goals or progress towards conservation objectives for the NWHI. The review process for proposed activities in the NWHI has benefited from the joint permitting process, but the primary activities that occur in the monument are still research, monitoring, restoration, species and asset management, and cultural activities that have little ecological impact. Though the partner agencies have successfully navigated the transition to institutional co-trusteeship, more tangible markers of successful management will be measured by how the agencies manage or respond to allochthonous threats such as climate change or marine debris accumulation as well as ecological restoration activities within the monument (e.g., rehabilitation of endangered and depleted species). For example, rapid or abrupt ecological shocks, such as a major coral bleaching event or disease outbreak, may elicit different institutional responses than longer-term and slower ecological changes [61]. Longer-term studies that link investigations of governance systems with specific management actions and ecological data will be necessary to more fully evaluate the efficacy of multi-agency collaboration as a model for US MPAs. 


\section{Conclusions}

Governance systems or the sets of rules (formal and informal) that determine how human systems and institutions interact remain an integral component for the successful management of complex, linked social-ecological systems. Put more simply, the rules that structure humanenvironment interactions are critical determinants of both social and environmental outcomes [82]. Ocean governance is moving towards increased collaboration, and multipleagency co-trusteeship is an emergent feature of larger MPAs and seascapes in the Pacific and beyond. Our results suggest that institutional co-trusteeship presents several barriers to effective planning and management and declines in efficiency, but institutional responses and increased maturity in the co-trusteeship have been successfully employed to reduce conflict and facilitate interagency interactions. The monument's multiple-agency governance structure has allowed for a unique examination of how partner agencies have reacted to collaborative governance and institutional co-trusteeship, which remains a central problem and focus in ocean and coastal management [83-85]. As one respondent put it, "We need to break down the barriers [between] county, state and federal. We need to break down the barriers between this department and that department...taxpayers and the general public...have an expectation that government works together." The institutional co-trusteeship created for the NWHI remains a unique model in US marine conservation, and new US marine national monuments and other existing and proposed MPAs in the Pacific have similarly unique governance structures that require institutional collaboration. Understanding the multiscale social processes that influence collaborative governance arrangements in MPAs is critical in determining the successful pathways to EBM.

\section{Acknowledgments}

The authors thank Kem Lowry, Laura A. A. LaFrance, Henrik Österblom, and Bruce A. Wilcox for their direction and comments on the research and manuscript, which greatly improved the clarity of our work. The authors also thank all of the individuals who were interviewed for participating in this paper and in particular the lead managers from the co-trustee agencies for their support in pursuing this project. This research was supported by the National Science Foundation (NSF) IGERT Award no. 0549514, NSF DDRI Award no. 0926768, and the Pew Institute for Ocean Sciences. Research was performed under IRB certificate of exemption no. 16780 from the Committee on Human Studies at the University of Hawai' $i$.

\section{References}

[1] M. Spalding, C. Ravilious, and E. P. Green, World Atlas of Coral Reefs, University of California Press, Berkeley, Calif, USA, 2001.

[2] E. Whittingham, J. Campbell, and P. Townsley, Poverty and Reefs: A Global Overview, Intergovernmental Oceanographic
Commission of UNESCO, Paris, France, 2003, DFID-IMMIOC/UNESCO, http://www.reefbase.org/key_topics/poverty_ and_reefs.aspx.

[3] P. V. Kirch and T. L. Hunt, Eds., Historical Ecology in the Pacific Islands: Prehistoric Environmental and Landscape Change, Yale University Press, New Haven, Conn, USA, 1997.

[4] J. D. Bell, M. Kronen, A. Vunisea et al., "Planning the use of fish for food security in the Pacific," Marine Policy, vol. 33, no. 1, pp. 64-76, 2009.

[5] R. E. Johannes, Words of the Lagoon: Fishing and Marine Lore in the Palau District of Micronesia, University of California Press, Berkeley, Calif, USA, 1981.

[6] J. E. Cinner, T. Daw, and T. R. McClanahan, "Socioeconomic factors that affect artisanal fishers' readiness to exit a declining fishery," Conservation Biology, vol. 23, no. 1, pp. 124-130, 2009.

[7] C. Wilkinson, Ed., Status of Coral Reefs of the World, Global Coral Reef Monitoring Network and Reef and Rainforest Research Centre, Townsville, Australia, 2008.

[8] J. M. Pandolfi, R. H. Bradbury, E. Sala et al., "Global trajectories of the long-term decline of coral reef ecosystems," Science, vol. 301, no. 5635, pp. 955-958, 2003.

[9] J. B. C. Jackson, M. X. Kirby, W. H. Berger et al., "Historical overfishing and the recent collapse of coastal ecosystems," Science, vol. 293, no. 5530, pp. 629-637, 2001.

[10] The World Bank, "Scaling up marine management: the role of marine protected areas," Tech. Rep. 36635 , GLB. The World Bank, Washington, DC, USA, 2006, http://go.worldbank.org/HI04V9I0Z0.

[11] D. R. Bellwood, T. P. Hughes, C. Folke, and M. Nyström, "Confronting the coral reef crisis," Nature, vol. 429, no. 6994, pp. 827-833, 2004.

[12] K. David Hyrenbach, K. A. Forney, and P. K. Dayton, "Marine protected areas and ocean basin management," Aquatic Conservation: Marine and Freshwater Ecosystems, vol. 10, no. 6, pp. 437-458, 2000.

[13] C. M. Roberts, B. Halpern, S. R. Palumbi, and R. R. Warner, "Designing marine reserve networks: why small, isolated protected areas are not enough," Conservation in Practice, vol. 2, no. 3, pp. 10-17, 2001.

[14] B. S. Halpern, S. E. Lester, and K. L. McLeod, "Placing marine protected areas onto the ecosystem-based management seascape," Proceedings of the National Academy of Sciences, http://www.pnas.org/content/early/2010/02/16/ 0908503107.abstract. In press.

[15] K. L. McLeod and H. M. Leslie, "Why ecosystem-based management?" in Ecosystem-Based Management for the Oceans, K. L. McLeod and H. M. Leslie, Eds., pp. 3-12, Island Press, Washington, DC, USA, 2009.

[16] K. L. McLeod, J. Lubchenco, S. R. Palumbi, and A. A. Rosenberg, "Scientific consensus statement on marine ecosystembased management," The Communication Partnership for Science and the Sea (COMPASS), 2005.

[17] M. Ruckelshaus, T. Klinger, N. Knowlton, and D. P. DeMaster, "Marine ecosystem-based management in practice: scientific and governance challenges," BioScience, vol. 58, no. 1, pp. 5363, 2008.

[18] H. M. Leslie and K. L. McLeod, "Confronting the challenges of implementing marine ecosystem-based management," Frontiers in Ecology and the Environment, vol. 5, no. 10, pp. 540$548,2007$.

[19] K. McLeod and H. Leslie, Eds., Ecosystem-Based Management for the Oceans: Resilience Approaches, Island Press, Washington, DC, USA, 2009. 
[20] K. K. Arkema, S. C. Abramson, and B. M. Dewsbury, "Marine ecosystem-based management: from characterization to implementation," Frontiers in Ecology and the Environment, vol. 4, no. 10, pp. 525-532, 2006.

[21] P. Christie, "Marine protected areas as biological successes and social failures in southeast Asia," in Aquatic Protected Areas as Fisheries Management Tools: Design, Use, and Evaluation of These Fully Protected Areas, J. B. Shipley, Ed., pp. 155-164, American Fisheries Society, Bethesda, Md, USA, 2004.

[22] P. Christie, B. J. McCay, M. L. Miller et al., "Toward developing a complete understanding: a social science research agenda for marine protected areas," Fisheries, vol. 28, no. 12, pp. 22-26, 2003.

[23] M. B. Mascia, "The human dimension of coral reef marine protected areas: recent social science research and its policy implications," Conservation Biology, vol. 17, no. 2, pp. 630632, 2003.

[24] M. B. Mascia, J. P. Brosius, T. A. Dobson et al., "Conservation and the social sciences," Conservation Biology, vol. 17, no. 3, pp. 649-650, 2003.

[25] R. S. Pomeroy, M. B. Mascia, and R. B. Pollnac, "Marine protected areas: the social dimension," in Report and Documentation of the Expert Workshop on Marine Protected Areas and Fisheries Management: Review of Issues and Considerations, Food and Agricultural Organization, Ed., pp. 149-181, Food and Agricultural Organization of the United Nations, Rome, Italy, 2006, FAO Fisheries Report no. 825 FIEP/R825.

[26] J. E. Cinner, "Designing marine reserves to reflect local socioeconomic conditions: lessons from long-enduring customary management systems," Coral Reefs, vol. 26, no. 4, pp. 10351045, 2007.

[27] S. Hanna, "Managing the human-ecological interface: marine resources as example and laboratory," Ecosystems, vol. 4, no. 8, pp. 736-741, 2001.

[28] J. N. Kittinger, K. N. Duin, and B. A. Wilcox, "Commercial fishing, conservation and compatibility in the Northwestern Hawaiian Islands," Marine Policy, vol. 34, no. 2, pp. 208-217, 2010.

[29] T. P. Hughes, L. H. Gunderson, C. Folke et al., "Adaptive management of the great barrier reef and the grand canyon world heritage areas," Ambio, vol. 36, no. 7, pp. 586-592, 2007.

[30] P. Olsson, C. Folke, and T. P. Hughes, "Navigating the transition to ecosystem-based management of the Great Barrier Reef, Australia," Proceedings of the National Academy of Sciences of the United States of America, vol. 105, no. 28, pp. 9489-9494, 2008.

[31] L. Fernandes, J. Day, A. Lewis et al., "Establishing representative no-take areas in the great barrier reef: largescale implementation of theory on marine protected areas," Conservation Biology, vol. 19, no. 6, pp. 1733-1744, 2005.

[32] J. C. Day, "Zoning-lessons from the Great Barrier Reef Marine Park," Ocean and Coastal Management, vol. 45, no. 2-3, pp. 139-156, 2002.

[33] R. Pollnac, P. Christie, J. E. Cinner et al., "Marine reserves as linked social-ecological systems," Proceedings of the National Academy of Sciences, http://www.pnas.org/content/early/2010/ 02/16/0908266107.abstract. In press.

[34] A. Charles and L. Wilson, "Human dimensions of marine protected areas," ICES Journal of Marine Science, vol. 66, no. 1, pp. 6-15, 2009.

[35] K. P. Emory, Archaeology of Nihoa and Necker Islands, Bishop Museum, Honolulu, Hawaii, USA, 1928.
[36] P. L. Cleghorn, The Settlement and Abandonment of Two Hawaiian Outposts: Nihoa and Necker Islands, Bernice P. Bishop Museum, Honolulu, Hawaii, USA, 1988, occasional papers.

[37] K. Kikiloi, "Rebirth of an archipelago: sustaining a Hawaiian cultural identity for people and homeland," in Hulili: Multidisplinary Research on Hawaiian Well-Being, vol. 6, pp. 73-114, 2010.

[38] C. Folke, F. S. Chapin III, and P. Olsson, "Transformations in ecosystem stewardship," in Principles of Ecosystem Stewardship: Resilience-Based Natural Resource Management in a Changing World, F. S. Chapin III, G. P. Kofinas, and C. Folke, Eds., Springer, Berlin, Germany, 2009.

[39] E. E. DeMartini and A. M. Friedlander, "Spatial patterns of endemism in shallow-water reef fish populations of the Northwestern Hawaiian Islands," Marine Ecology Progress Series, vol. 271, pp. 281-296, 2004.

[40] J. Maragos and D. Gulko, Eds., Coral Reef Ecosystems of the Northwestern Hawaiian Islands: Interim Results Emphasizing the 2000 Surveys, U.S. Fish and Wildlife Service and Hawaii Department of Land and Natural Resources, Honolulu, Hawaii, USA, 2002.

[41] A. Friedlander et al., "The state of coral reef ecosystems of the Northwestern Hawaiian Islands," in The State of Coral Reef Ecosystems of the United States and Pacific Freely Associated States, J. E. Waddell and A. M. Clarke, Eds., vol. 73 of NOAA Technical Memorandum NOS NCCOS, pp. 263-306, NOAA/NCCOS Center for Coastal Monitoring and Assessment's Biogeography Team, Silver Spring, Md, USA, 2008.

[42] J. N. Kittinger, Historical ecology of coral reefs in the Hawaiian Archipelago, Ph.D. dissertation, Department of Geography, University of Hawaii at Mānoa, Honolulu, Hawaii, USA, 2010.

[43] A. M. Friedlander and E. E. DeMartini, "Contrasts in density, size, and biomass of reef fishes between the northwestern and the main Hawaiian Islands: the effects of fishing down apex predators," Marine Ecology Progress Series, vol. 230, pp. 253264, 2002.

[44] M. J. Rauzon, Isles of Refuge: Wildlife and History of the Northwestern Hawaiian Islands, University of Hawaii Press, Honolulu, Hawaii, USA, 2001.

[45] R. J. Shallenberger, "History of management in the Northwestern Hawaiin Islands," Atoll Research Bulletin, no. 543, pp. 2331,2006

[46] American Antiquities Act of 1906, 16 U.S.C. 431-433.

[47] Department of Commerce et al., "Final Rule, Northwestern Hawaiian Islands Marine National Monument," 2006, 71 Fed. Reg. 51134, Washington, DC, USA, August 2006.

[48] K. A. Selkoe, B. S. Halpern, C. M. Ebert et al., "A map of human impacts to a "pristine" coral reef ecosystem, the Papahānaumokuākea Marine National Monument," Coral Reefs, vol. 28, no. 3, pp. 635-650, 2009.

[49] K. A. Selkoe, B. S. Halpern, and R. J. Toonen, "Evaluating anthropogenic threats to the Northwestern Hawaiian Islands," Aquatic Conservation: Marine and Freshwater Ecosystems, vol. 18, no. 7, pp. 1149-1165, 2008.

[50] B. Stieglitz, "New Hawaiian national monument," 2006, SENRA Newsletter, October 2006. Section on Environmental and Natural Resource Administration (SENRA) of the American Society for Public Administration, pp. 2-4.

[51] M. J. Donohue, "How multiagency partnerships can successfully address large-scale pollution problems: a Hawaii case study," Marine Pollution Bulletin, vol. 46, no. 6, pp. 700-702, 2003. 
[52] D. M. Lavigne, "The Hawaiian monk seal: management of an endangered species," in Conservation and Management of Marine Mammals, J. R. Twiss Jr. and R. R. Reeves, Eds., pp. 246-266, Smithsonian Institution Press, Washington, DC, USA, 1999.

[53] Memorandum of Agreement, "Memorandum of Agreement Among the State of Hawaii Department of Land and Natural Resources, and the U.S. Department of the Interior, U.S. Fish and Wildlife Service, and the U.S. Department of Commerce, National Oceanic and Atmospheric Administration for Promoting Coordinated Management of the Northwestern Hawaiian Islands Marine National Monument," Honolulu, Hawaii, USA, December 2006.

[54] H. R. Bernard, Research Methods in Anthropology: Qualitative and Quantitative Approaches, AltaMira Press, Oxford, UK, 2006.

[55] M. B. Miles and A. M. Huberman, Qualitative Data Analysis: An Expanded Sourcebook, Sage, Thousand Oaks, Calif, USA, 1994.

[56] B. Glaser and A. Strauss, The Discovery of Grounded Theory: Strategies for Qualitative Research, Aldine, New York, NY, USA, 1967.

[57] P. Martin and B. Turner, "Grounded theory and organizational research," Journal of Applied Behavioral Science, vol. 22, no. 2, pp. 141-157, 1986.

[58] L. Schatzman, "Dimensional analysis: notes on an alternative approach to the grounding of theory on qualitative research," in Social Organization and Social Process: Essays in Honor of Anselm Strauss, D. R. Maines, Ed., pp. 303-314, Aldine, New York, NY, USA, 1991.

[59] L. Robrecht, "Grounded theory: evolving methods," Qualitative Health Research, vol. 5, pp. 169-177, 1995.

[60] G. Thomas and D. James, "Reinventing grounded theory: some questions about theory, ground and discovery," British Educational Research Journal, vol. 32, no. 6, pp. 767-795, 2006.

[61] P. Olsson, C. Folke, V. Galaz, T. Hahn, and L. Schultz, "Enhancing the fit through adaptive co-management: creating and maintaining bridging functions for matching scales in the Kristianstads Vattenrike Biosphere Reserve, Sweden," Ecology and Society, vol. 12, no. 1, article 28, 2007.

[62] E. Ostrom, "Scales, polycentricity, and incentives: designing complexity to govern complexity," in Protection of Global Biodiversity: Converging Strategies, L. D. Guruswamy and J. A. McNeely, Eds., pp. 149-167, Duke University Press, Durham, NC, USA, 1998.

[63] M. T. Imperial, "Institutional analysis and ecosystem-based management: the institutional analysis and development framework," Environmental Management, vol. 24, no. 4, pp. 449-465, 1999.

[64] C. Folke et al., "Resilience thinking: integrating resilience, adaptability and transformability," Ecology and Society. In press.

[65] C. Argyris and D. A. Schön, Organizational Learning: A Theory of Action Perspective, Addison-Wesley, Reading, Mass, USA, 1978.

[66] C. M. Fiol and M. A. Lyles, "Organizational learning," Academy of Management Review, vol. 10, no. 4, pp. 803-813, 1985.

[67] F. Berkes, J. Colding, and C. Folke, Navigating Social-Ecological Systems: Building Resilience for Complexity and Change, Cambridge University Press, Cambridge, UK, 2003.

[68] C. Folke, T. Hahn, P. Olsson, and J. Norberg, "Adaptive governance of social-ecological systems," Annual Review of Environment and Resources, vol. 30, no. 1, pp. 441-473, 2005.
[69] I. Fazey, J. A. Fazey, J. Fischer et al., "Adaptive capacity and learning to learn as leverage for social-ecological resilience," Frontiers in Ecology and the Environment, vol. 5, no. 7, pp. 375380, 2007.

[70] D. North, Institutions, Institutional Change, and Economic Performance, Cambridge University Press, Cambridge, UK, 1990.

[71] P. Olsson, Ö. Bodin, and C. Folke, "Building transformative capacity for ecosystem stewardship in social-ecological systems," in Adaptive Capacity and Environmental Governance, D. Armitage and R. Plummer, Eds., Springer Series on Environmental Management, pp. 263-285, Springer, New York, NY, USA, 2010.

[72] USCOP, An Ocean Blueprint for the 21st Century, U. S. Commission on Ocean Policy (USCOP), Washington, DC, USA, 2004.

[73] POC, America's Living Oceans: Charting a Course for Sea Change. A Report to the Nation. Recommendations for a New Ocean Policy, Pew Oceans Commission (POC), The Pew Charitable Trusts, Arlington, Va, USA, 2003.

[74] T. M. Koontz and C. W. Thomas, "What do we know and need to know about the environmental outcomes of collaborative management?" Public Administration Review, vol. 66, no. 1, pp. 111-121, 2006.

[75] T. Dietz, E. Ostrom, and P. C. Stern, "The struggle to govern the commons," Science, vol. 302, no. 5652, pp. 1907-1912, 2003.

[76] E. Ostrom, J. Burger, C. B. Field, R. B. Norgaard, and D. Policansky, "Revisiting the commons: local lessons, global challenges," Science, vol. 284, no. 5412, pp. 278-282, 1999.

[77] C. S. Holling, Adaptive Environmental Assessment and Management, John Wiley \& Sons, London, UK, 1978.

[78] C. S. Holling and G. K. Meffe, "Command and control and the pathology of natural resource management," Conservation Biology, vol. 10, no. 2, pp. 328-337, 1996.

[79] N. Salafsky, R. Margoluis, and K. Redford, Adaptive Management: A Tool for Conservation Practitioners, Biodiversity Support Program, Washington, DC, USA, 2001.

[80] L. H. Gunderson and C. S. Holling, Eds., Panarchy: Understanding Transformations in Human and Natural Systems, Island Press, Washington, DC, USA, 2002.

[81] L. H. Gunderson, C. S. Holling, and S. S. Light, Barriers and Bridges to the Renewal of Ecosystems and Institutions, Columbia University Press, New York, NY, USA, 1995.

[82] G. Brennan and J. Buchanan, The Reason of Rules: Constitutional Political Economy, Cambridge University Press, Cambridge, UK, 1986.

[83] L. B. Crowder, G. Osherenko, O. R. Young et al., "Resolving mismatches in U.S. ocean governance," Science, vol. 313, no. 5787, pp. 617-618, 2006.

[84] Interagency Ocean Policy Task Force, "Interim Report of the Interagency Ocean Policy Task Force," September 2009, The Executive Office of the President, The White House Council on Environmental Quality and the Interagency Ocean Policy Task Force: Washington, DC, USA.

[85] The White House, "National Policy for the Oceans, Our Coasts, and the Great Lakes," 2009, Memorandum for the Heads of Executive Departments and Agencies, June 2009, Office of the Press Secretary, The White House: Washington, DC, USA. 

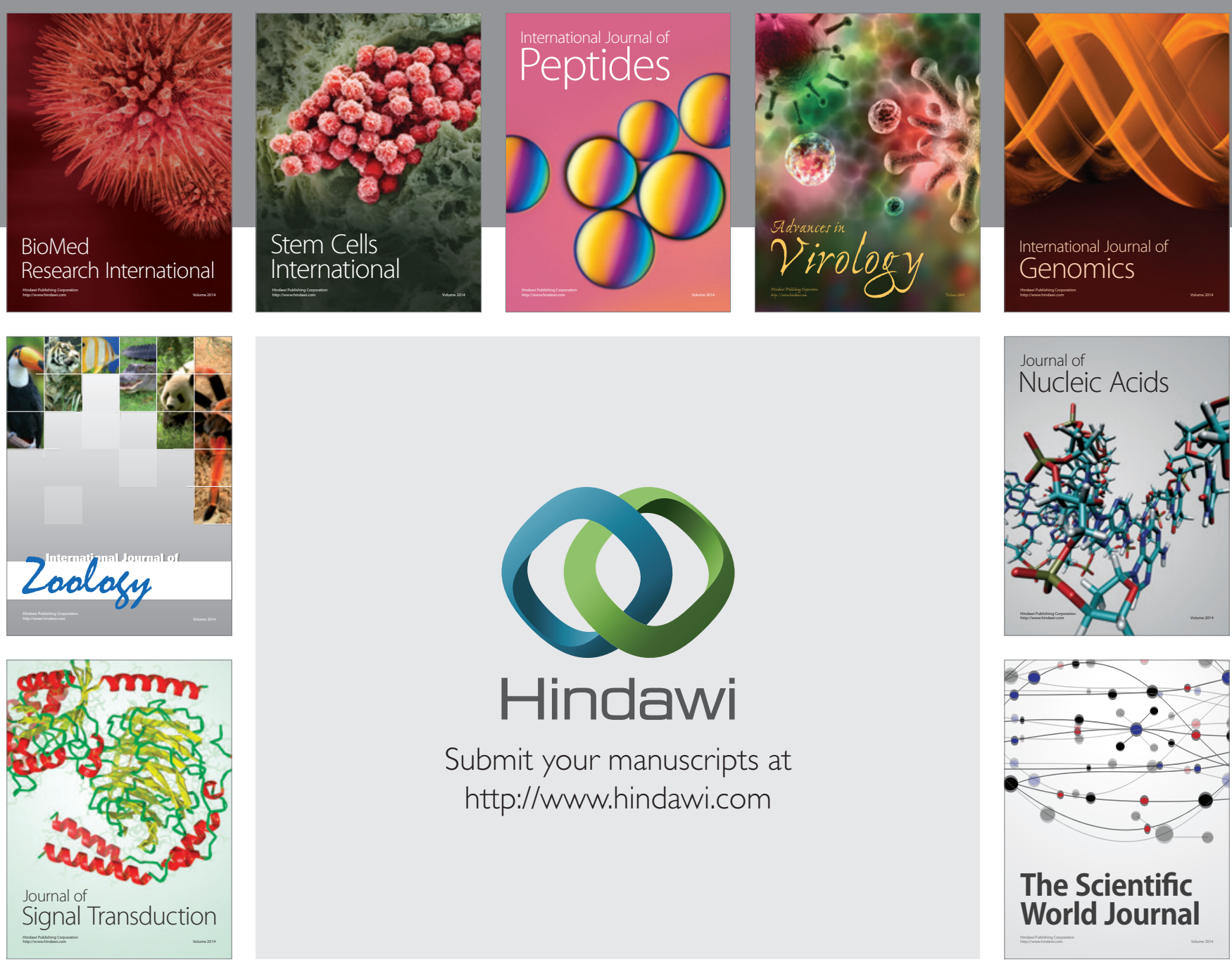

Submit your manuscripts at

http://www.hindawi.com
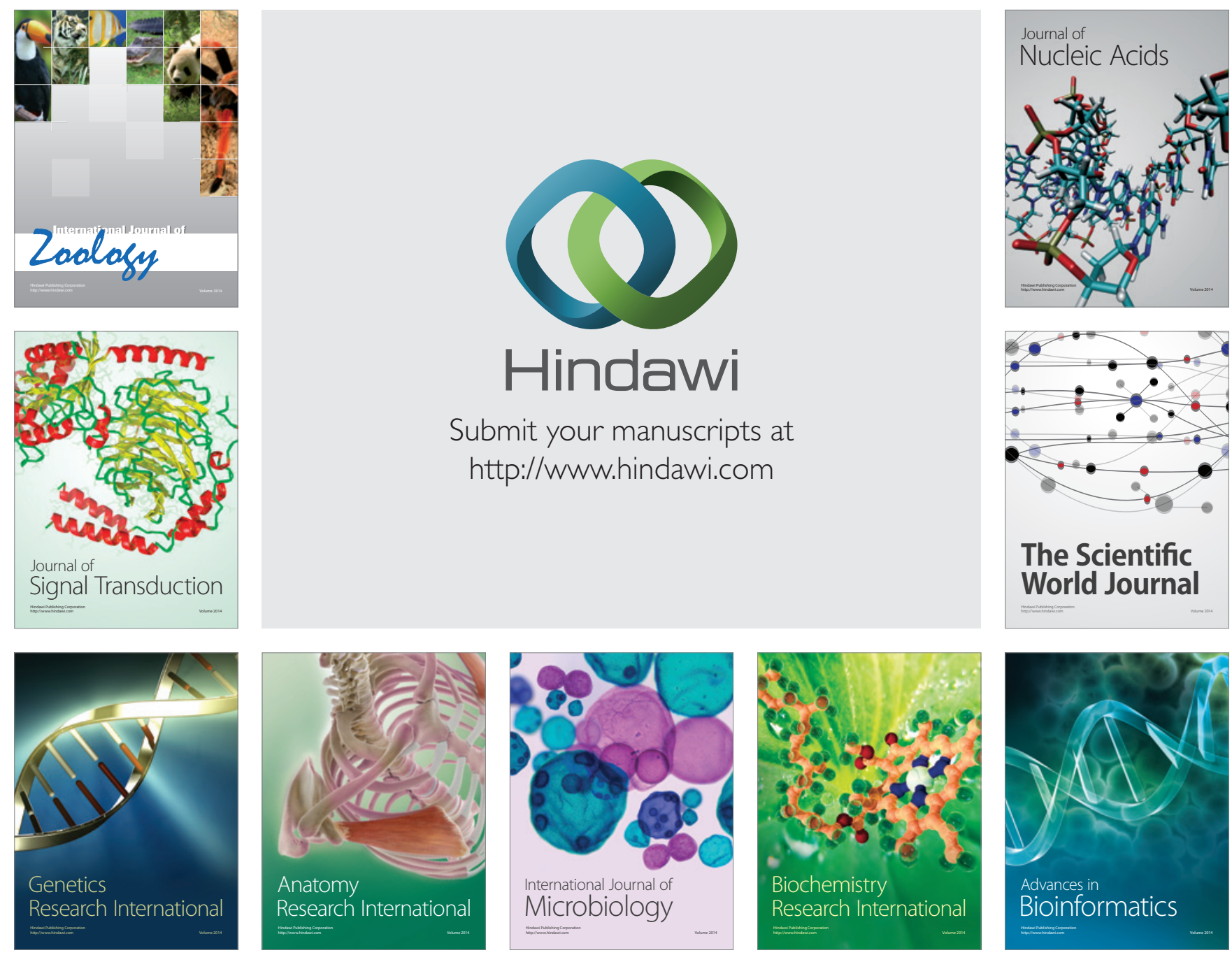

The Scientific World Journal
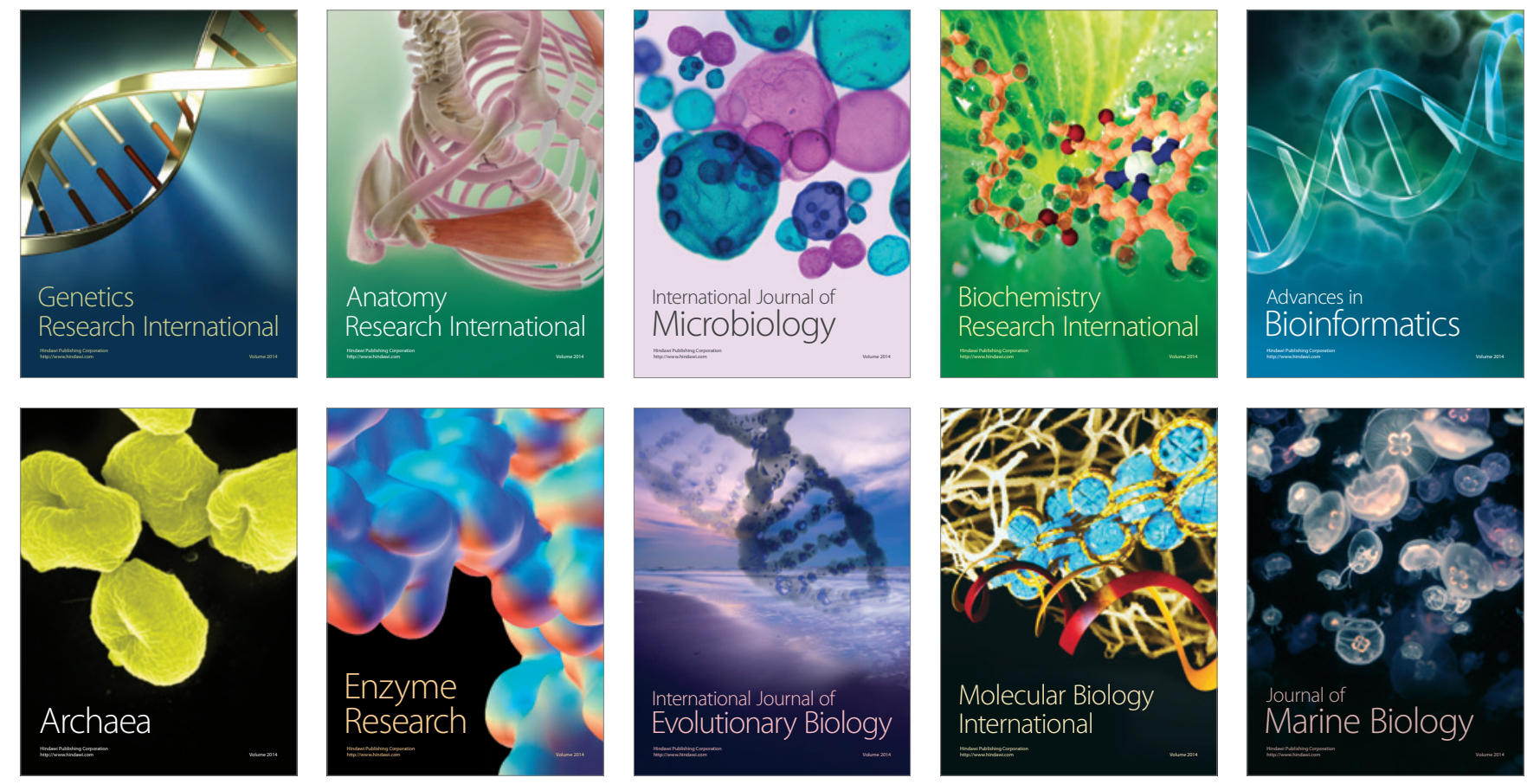